\title{
An artificial intelligent approach for the optimization of organic rankine cycle power generation systems
}

Jian Ding Tan, Chin Wai Lim, Siaw Paw Koh, Sieh Kiong Tiong, Ying Ying Koay

Institute of Sustainable Energy (ISE), Universiti Tenaga Nasional, Selangor, Malaysia

\begin{tabular}{|c|c|}
\hline Article Info & ABSTRACT \\
\hline Article history: & \multirow{8}{*}{$\begin{array}{l}\text { The study on Organic Rankine Cycle (ORC) power generation system has } \\
\text { gained significant popularity among researchers over the past decade, mainly } \\
\text { due to the financial and environmental benefits that the system provides. A } \\
\text { good maximum power point tracking (MPPT) mechanism can push the } \\
\text { efficiency of an ORC to a higher rate. In this research, a Self-Adjusted Peak } \\
\text { Search algorithm (SAPS) is proposed as the MPPT scheme of an ORC } \\
\text { system. The SAPS has the ability to perform a relatively detailed search } \\
\text { when the convergence reaches the near-optima peak without jeopardizing the } \\
\text { speed of the overall convergence process. The SAPS is tested in a simulation } \\
\text { to track for a moving maximum power pint (MPP) of an ORC system. } \\
\text { Experiment results show that the SAPS outperformed several other well- } \\
\text { established optimization algorithm in tracking the moving MPP, especially in } \\
\text { term of the solution accuracies. It can thus be concluded that the proposed } \\
\text { SAPS performs well as a mean of an MPPT scheme in an ORC system. }\end{array}$} \\
\hline Received Aug 9, 2018 & \\
\hline Revised Oct 30, 2018 & \\
\hline Accepted Dec 18, 2018 & \\
\hline Keywords: & \\
\hline Artificial intelligent & \\
\hline MPPT & \\
\hline Organic rankine cycle & \\
\hline
\end{tabular}

Copyright (C) 2019 Institute of Advanced Engineering and Science. All rights reserved.

\section{Corresponding Author:}

Jian Ding Tan Name of Corresponding Author, Institute of Sustainable Energy (ISE), Universiti Tenaga Nasional, 43000 Kajang, Selangor, Malaysia.

Email: tjianding@uniten.edu.my

\section{INTRODUCTION}

Over the past few decades, researchers around the world has been working for methods to enhance the efficiency of power generation systems and ways to improve them. The heat waste from power generation plants and huge engines has become a point of interest for energy recovery and optimization [1]. Research on such low temperature energy recovery systems is important not only as a mean to provide additional power generation, but also to reduce the negative impact of the heat waste to the climate and environment.

Organic Rankine Cycle (ORC) is a heat waste based power generation system designed with high adaptability for implementations in a wide range of energy sources [2]. The past decade shows rapid research and implementation of ORC systems in the effort to improve the overall efficiency of conventional energy generation systems. Generally speaking, an ORC system consists of four major components, namely the evaporator, the expander, the pump and the condenser. Organic working fluid is initially boiled under pressure to make high-pressure vapour. This vapour then turns the turbine while passes through the expander, which in turn, generates electricity. The low-pressure vapour then flows to the condenser. At this stage, the vapour condenses to liquid phase. The low-pressure liquid working fluid is then pumped to the evaporator and the cycle restarts.

Compared to other turbine-based power generation systems, ORCs can be implemented to a wide variety of heat sources, such as solid fuels, concentrated solar energy, geothermal heat, and even industrial heat wastes. The ORC has multiple advantages, such as the simplicity of the system and the adoption of organic working fluid instead of water [3]. Generally speaking, organic fluid has relatively lower boiling 
point to that of the water. This essential feature makes the ORC systems suitable to be implemented at low temperatures and pressures [4]. It can be found in the literature that the ORC systems are effectively used for waste heat recovery from internal combustion engines exhaust $[5,6]$ and also from industrial processes $[7,8]$. This provides financial benefit as the recovered energy which otherwise would be released to the environment can now be converted to electricity, in the meanwhile reduces greenhouse gas emission $[9,10]$. ORCs are also found to be auxiliaries in several types of power generation systems, such as biomass $[11,12]$, concentrated solar thermal [13,14], geothermal [15,16], ocean thermal energy conversion $[17,8]$ and combined heat and power systems $[19,20]$.

The contribution of this paper is twofold and can be generally described as follows. First, a SelfAdjusting Peak Search algorithm (SAPS) is proposed. This search mechanism has the ability to perform a relatively detailed search without jeopardizing the speed of the overall convergence process. Secondly, a new maximum power point tracking (MPPT) mechanism for an ORC system is proposed by implementing the developed SAPS algorithm. Simulations are carried out to validate the performance of the SAPS in tracking the moving maximum power point (MPP) of an ORC system.

\section{MPPT OF AN ORC}

In a constant temperature and flow rate, the conversion efficiency of a power generation system is directly proportional to the saturation temperature [21]. Literature study shows that the flow rate of the working fluid has significant impact on the output power of the system [22]. An optimal working fluid flow rate grants an optimal power generation rate. Higher or lower flow rate can cause unnecessary losses to the overall power generation of the system. Thus, a maximum power point tracking (MPPT) mechanism is important to ensure a maximum power generation from an ORC system. The general idea of an MPPT mechanism in an ORC is to maximize the power generation by controlling the flow rate of the working fluid. The MPPT scheme calculates the power output by measuring the output current and voltage, and adjust the speed of the pump accordingly by varying the voltage via pulse width modulation (PWM). Figure 1. shows a simple MPPT mechanism for an ORC system [23].

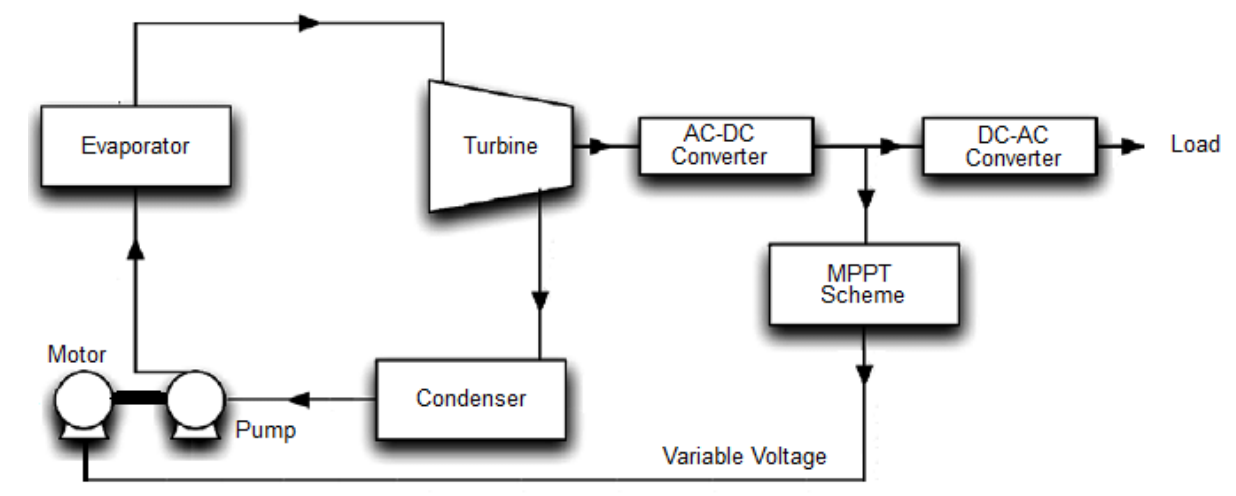

Figure 1. MPPT scheme in an ORC system

\section{SELF-ADJUSTED PEAK SEARCH ALGORITHM}

In this research, a Self-Adjusted Peak Search algorithm (SAPS) is proposed for the MPPT scheme of the ORC. The proposed SAPS an enhanced optimization mechanism that can grant the algorithm the ability to hit a more accurate solution without heavily slowing down the entire convergence process. The general idea of the SAPS is to begin the search with a relatively larger search steps. As the iterations go, the SAPS automatically adjust and regulate the size of the search steps. This feature gives the SAPS the ability to perform a much detailed search, which in turn leads to a better optimized solution.

The SAPS initializes with randomly tabulated solution particles within the feasible PWM duty ratio. Then, each particle begins the exploration for higher power generation by a two-way probing, one way probes towards the upper limit and the other probes towards the lower limit of the duty cycle value. The probing begins with relatively larger search steps. When both probes returned with no higher power, the SAPS readjusts the search step length using the equation as shown in equation (1). This non-linear equation is specially designed to co-relate the current iteration number and the size of the required search step. In 
equation (1), i represents the current number of local search iteration while Max_LSIte refers to the pre-set maximum number of iteration.

$$
L=\frac{2}{1+\exp \left(\frac{10 i}{\text { Max_LSIte }}\right)}
$$

Table 1. shows the search and adjustment mechanism of the proposed SAPS. The decision flow is further depicted and illustrated in Figure 2.

Table 1. The search and adjust mechanism of the proposed SAPS for the MPPT of an ORC

\begin{tabular}{|c|c|}
\hline \multicolumn{2}{|r|}{$\begin{array}{l}\text { Self-Adjusted Peak Search (SAPS) } \\
\end{array}$} \\
\hline Step 1 & Set maximum number of iteration as terminating criteria. \\
\hline Step 2 & Calculate the length of the probes using equation (1). \\
\hline Step 4 & Check if any of the solutions returned are within feasible range. \\
\hline Step 5 & Compare the new found solutions and move particle towards the better yield. \\
\hline Step 7 & From the new found duty ratio, repeat Steps 3 to 7 until no any higher output can be found. \\
\hline Step 8 & $\begin{array}{l}\text { Exit if the iteration number reaches termination criteria. Else, adjust the probe length, move on to the next } \\
\text { iteration }(i=i+1) \text { and repeat from Step } 2 \text {. }\end{array}$ \\
\hline
\end{tabular}

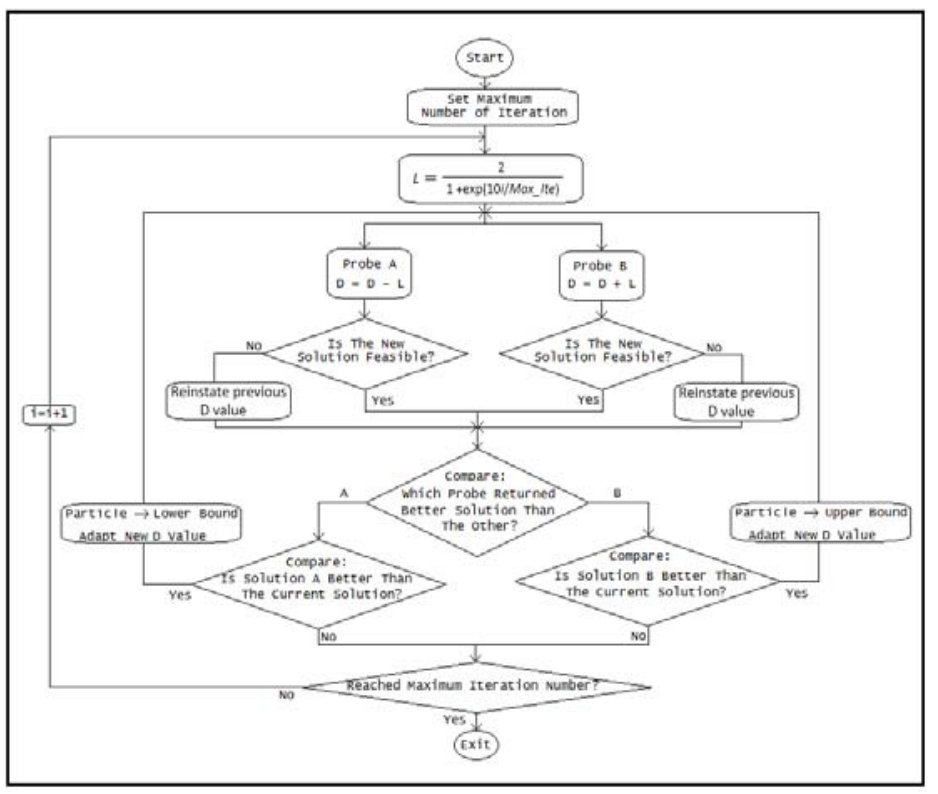

Figure 2. The decision flow of the proposed SAPS, where D refers to the duty ratio of the PWM to be fed into the voltage regulator and $\lambda$ denotes the search step size

\section{EXPERIMENTAL RESULTS}

Simulations were carried out to validate and investigate the performance of the proposed algorithm in tracking the MPP of the ORC. To simulate a more realistic test, the MPP was designed to change and move from one value to another. The first MPP in this experiment was set to be $14.73 \mathrm{~kW}$ at $63.1 \%$ duty cycle of PWM feed. After a while, the value moved to $15.32 \mathrm{~kW}$ at $75.22 \%$ duty cycle. The proposed SAPS was tested in the simulation to track for the moving MPP. The performance of the SAPS is benchmarked with that of some other well- established search algorithms found in the literature, including the Random 
Step-size Hill Climbing (RSHC) and Genetic Algorithm (GA). In order to ease the benchmarking and to have a fair comparison, 10 solution particles were used in both SAPS and RSHC. The number of the chromosomes employed in the GA was also set to 10 . The simulations were carried out with a $1.6 \mathrm{GHz}$ Intel i5 processor in Windows-7 operating system with 4 gigabytes of RAM. 10 independent runs were carried out to avoid stochastic discrepancy.

The performance of all the developed algorithms in tracking the moving MPP are analysed. Table 2. shows the performance of each algorithm in tracking the first MPP, which was set to be $14.73 \mathrm{~kW}$. The comparisons are sectioned into the best solutions, worst solutions, average solutions and the standard deviations from the 10 independent runs. Table 2 shows the performance comparison of the SAPS and the other benchmarks in tracking the second MPP, which was set at $15.32 \mathrm{~kW}$. From Table 1. and Table 2. all the algorithms successfully found both the static MPPs. However, it can be observed that the propose SAPS outperformed other benchmarks in term of accuracy as the solutions returned by the SAPS found relatively higher power generation. The GenCo generation system consists of 15 thermal units. Table 2. shows data of the thermal units with an initial status of units at the beginning of the planning period.

Table 2. Performance comparison of the first MPP searching, set at $14.73 \mathrm{~kW}$

\begin{tabular}{llll}
\hline & SAPS & RSHC & GA \\
\hline Best Solution & $\mathbf{1 4 . 7 3}$ & 14.71 & 14.67 \\
Wost Solution & $\mathbf{1 4 . 7 1}$ & 14.23 & 14.27 \\
Average Solution & $\mathbf{1 4 . 7 3}$ & 14.45 & 14.55 \\
SD & $\mathbf{5 . 7 1 E - 0 4}$ & $7.78 \mathrm{E}-03$ & $6.83 \mathrm{E}-02$ \\
\hline
\end{tabular}

Table 3. shows the performance comparison of the SAPS and the other benchmarks in tracking the second MPP, which was set at 15.32kW. From Table 1 and Table 2, all the algorithms successfully found both the static MPPs. However, it can be observed that the propose SAPS outperformed other benchmarks in term of accuracy as the solutions returned by the SAPS found relatively higher power generation.

Table 3: Performance comparison of the second MPP searching, set at $15.32 \mathrm{~kW}$

\begin{tabular}{llll}
\hline & SAPS & RSHC & GA \\
\hline Best Solution & $\mathbf{1 5 . 3 2}$ & 15.29 & 15.29 \\
Wost Solution & $\mathbf{1 5 . 3 1}$ & 15.2 & 15.07 \\
Average Solution & $\mathbf{1 5 . 3 2}$ & 15.23 & 15.18 \\
SD & $\mathbf{2 . 6 2 E - 0 5}$ & $6.61 \mathrm{E}-03$ & $1.72 \mathrm{E}-02$ \\
\hline
\end{tabular}

Figure 3. shows some randomly sampled convergence processes performed by each of the algorithms in tracking the moving MPP. It can be observed from the graph that proposed SAPS converge relatively faster in the initial stage of the search for both the MPPs. It also successfully achieved comparatively higher solutions, which in turn pushed the generated power higher.

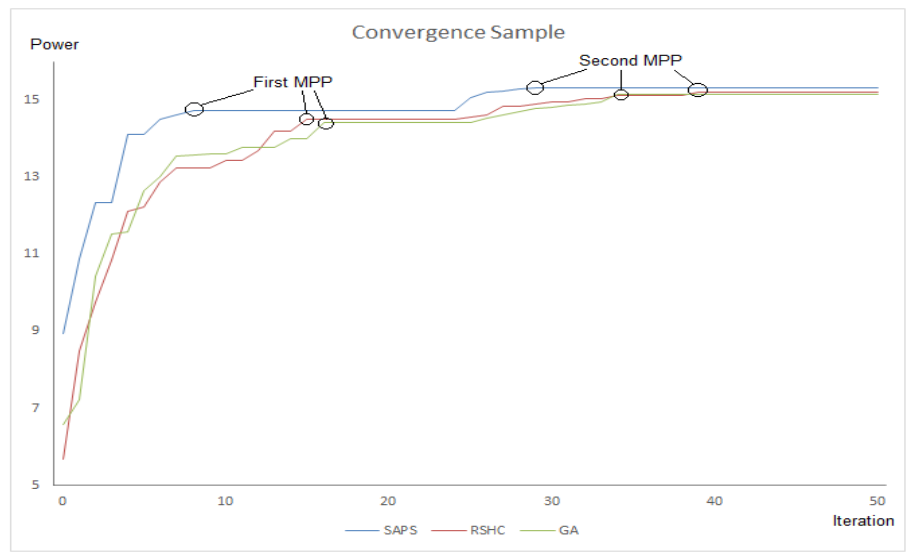

Figure 3. Convergence process sample comparison of SAPS, RSHC and GA 


\section{CONCLUSION}

In this research, a Self-Adjusted Peak Search algorithm (SAPS) is proposed. The proposed SAPS begins the search for optimal solutions in relatively larger steps, and regulates the search step sizes as the iterations go. This allows the SAPS to find solutions with higher accuracies quicker by not probing around too finely at the beginning of the search. Experiment outcomes show that the proposed SAPS performed well in tracking the maximum power point of an Organic Rankine Cycle power generation system. The results also show that the SAPS outperformed other well-established search mechanisms, including random step hillclimbing and genetic algorithm in the MPPT of ORC power generation systems.

\section{ACKNOWLEDGEMENTS}

The authors express great acknowledgement to UniversitiTenagaNasional (UNITEN), Malaysia for the support of this research.

\section{REFERENCES}

[1] P. Ziółkowski, T. Kowalczyk, S. Kornet, J. Badur, On low-grade waste heat utilization from a supercritical steam power plant using an ORC-bottoming cycle coupled with two sources of heat, Energy Convers Manage 2017,146, 158-173, 2017.

[2] T.C. Hung, T.Y. Shai, S.K. Wang, A review of organic rankine cycles (ORCs) for the recovery of low-grade waste heat, Energy, 22, 661-667, 1997. https://doi.org/10. 1016/S0360-5442(96)00165-X.

[3] P. Colonna, E. Casati, C. Trapp, Organic Rankine Cycle Power Systems: From the Concept to Current Technology, Applications, and an Outlook to the Future, Journal of Gas Turbines Power, 137(10), 100-101, 2015.

[4] M. White, A.I. Sayma, Improving the economy-of-scale of small organic rankine cycle systems through appropriate working fluid selection, Applied Energy, 183, 1227-1239, 2016.

[5] S. Lion, C.N. Michos, I. Vlaskos, C. Rouaud, R. Taccani, A review of waste heat recovery and Organic Rankine Cycles (ORC) in on-off highway vehicle heavy duty diesel engine applications, Renewable and Sustainable Energy Review, 79, 691-708, 2017.https://doi.org/10.1016/j.rser.2017.05.082.

[6] V. Chintala, S. Kumar, J.K. Pandey, A technical review on waste heat recovery from compression ignition engines using organic Rankine cycle, Renewable and Sustainable Energy Review, 81, 493-509, 2018. https://doi.org/10.1016/j.rser.2017.08.016.

[7] J. Larjola, Electricity from industrial waste heat using high-speed organic Rankine cycle (ORC), International Journal of Production and Economy, 41, 227-235, 1995. https://doi.org/10.1016/0925-5273(94)00098-0.

[8] F. Campana, M. Bianchi, L. Branchini, A. De Pascale, A. Peretto, M. Baresi, ORC waste heat recovery in European energy intensive industries: energy and GHG savings, Energy Conversion Management, 76, 244-252, 2013. https://doi.org/10.1016/j. enconman.2013.07.041.

[9] M. Imran M, B.S. Park, H.J. Kim, D.H. Lee, M. Usman, Economic assessment of greenhouse gas reduction through low-grade waste heat recovery using organic Rankine cycle (ORC), Journal of Mechanical Science Technology, 29, 835-843, 2015. https://doi.org/10.1007/s12206-015-0147-5.

[10] A. Karvountzis-Kontakiotis, A. Pesiridis, H. Zhao, F. Alshammari, B. Franchetti, I. Pesmazoglou, Effect of an ORC waste heat recovery system on diesel engine fuel economy for off-highway vehicles 2017. https://www.sae.org/publications/technical-papers/content/2017-01-0136/ https://doi.org/10.4271/2017-01-0136

[11] G. Qiu, Y. Shao, J. Li, H. Liu, S.B. Riffat, Experimental investigation of a biomass-fired ORC-based micro-CHP for domestic applications, Fuel, 96, 374-382, 2012. https://doi.org/10.1016/j.fuel.2012.01.028.

[12] M. Jradi, S. Riffat, Experimental investigation of a biomass-fuelled micro-scale trigeneration system with an organic Rankine cycle and liquid desiccant cooling unit,Energy, 71, 80-93, 2014.https://doi.org/10.1016/j.energy.2014.04.077.

[13] V.R. Patil, V.I. Biradar, R. Shreyas, P. Garg, M.S. Orosz, N.C. Thirumalai, Techno-economic comparison of solar organic Rankine cycle (ORC) and photovoltaic (PV) systems with energy storage, Renew Energy, 113, 1250-1260, 2017. https://doi.org/10.1016/j.renene.2017.06.107.

[14] M.S. Orosz, Small scale solar ORC system for distributed power in Lesotho, 29th ISES Bienn sol world congr 2009, 2, 1042-1048, 2009.

[15] R. DiPippo, Geothermal power plants: evolution and performance assessments, Geothermics, 53, 291-307, 2015. https://doi.org/10.1016/j.geothermics.2014.07.005.

[16] M. Imran M, M. Usman, B.S. Park, Y. Yang, Comparative assessment of Organic Rankine Cycle integration for low temperature geothermal heat source applications, Energy, 102, 473-90, 2016. https://doi.org/10.1016/j.energy.2016.02.119.

[17] H. Uehara, C.O. Dilao, T. Nakaoka, Conceptual design of ocean thermal energy conversion (OTEC) power plants in the Philippines, Solar Energy, 41, 431-441, 1988. https://doi.org/10.1016/0038-092X(88)90017-5.

[18] B.F. Tchanche, M. Pétrissans, G. Papadakis, Heat resources and organic Rankine cycle machines, Renewable and Sustainable Energy Review, 39, 1185-99, 2014. https://doi.org/10.1016/j.rser.2014.07.139.

[19] L. Tocci, T. Pal, I. Pesmazoglou, B. Franchetti, Small scale Organic Rankine Cycle (ORC): a techno-economic review, Energies, 10, 1-26. 2017. https://doi.org/10.3390/en10040413.

Indonesian J Elec Eng \& Comp Sci, Vol. 14, No. 1, April 2019 : 340 - 345 
[20] J. Navarro-Esbrí, F. Molés, B. Peris, A. Mota-Babiloni, K. Kontomaris, Experimental study of an Organic Rankine Cycle with HFO-1336mzz-Z as a low global warming potential working fluid for micro-scale low temperature applications, Energy, 133, 79-89, 2017. https://doi.org/10.1016/j.energy.2017.05.092.

[21] B. Saleh, G. Koglbauer, Working fluids for low-temperature organic Rankine cycles, Energy, 32, 1210-1221, 2007.

[22] V. Lemort, S. Quoilin, C. Cuevas, and J. Lebrun, Testing and modeling a scroll expander integrated into an Organic Rankine Cycle, Applied Thermal Engineering, 14-15, 3094-3102, 2009.

[23] G. Zhou, W. Li, S. Zhang, The maximum power point tracking (MPPT) of low temperature waste heat power generation system with Organic Rankine cycle (ORC), 2017 Chinese Automation Congress (CAC), 3661-3665, 2017. https://doi.org/10.1109/CAC.2017.8243416 